\title{
EFL university teachers' perspectives in written corrective feedback and their actual applications
}

\author{
Windy Wahju Purnomo, Yazid Basthomi, Johannes Ananto Prayogo \\ Graduate Program in English Language Teaching, Universitas Negeri Malang, Malang, Indonesia
}

\begin{tabular}{l} 
Article Info \\
\hline Article history: \\
Received Jan 28, 2021 \\
Revised Jun 18, 2021 \\
Accepted Jul 17, 2021 \\
\hline
\end{tabular}

\section{Keywords:}

Actual applications

Classroom teaching

EFL

Learning process

Written corrective feedback

\begin{abstract}
This study aimed to investigate the English as a foreign language (EFL) university teachers' perspective and their actual applications in providing written corrective feedback to the writing errors made by the EFL university students and their correlation. The study was based on 80 responses of a Google-Form survey distributed to EFL university teachers with various teaching experiences from the most parts of Indonesia. Correlational design was used in this research. Descriptive statistics and Pearson's correlation tests were used to analyze data. The results indicated that the majority of teachers had perspectives that it is valuable to provide and vary the strategies of written corrective feedback. In addition, the teachers mostly applied both direct and indirect feedback in various strategies and they only sometimes provided corrections in all aspects of errors and reformulation. It was also found out that the Indonesian EFL university teachers' perspectives in the written corrective on students' writing errors highly correlated with their actual applications. The results of the study provide both theoretical and pedagogical implications. Theoretically, it enriches the body knowledge of feedback and EFL writing. Pedagogically, EFL teachers are also suggested to improve their knowledge on various feedback techniques and apply it in their classroom teaching and learning process.
\end{abstract}

This is an open access article under the CC BY-SA license.

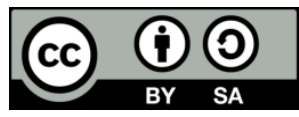

\author{
Corresponding Author: \\ Windy Wahju Purnomo \\ Graduate Program at English Language Teaching \\ Universitas Negeri Malang \\ No. 5 Semarang Street, Malang, 65145 Indonesia \\ Email: winyupur@gmail.com
}

\section{INTRODUCTION}

Corrective feedback is one of the important elements in the process of learning and teaching in general and it is also essential in foreign language learning. Corrective feedback commonly concerns with the corrections and comments of linguistics errors that the learners receive in connection with their performance of learning second or foreign language. The issues of sources, strategies, effects and follows up written feedback provision have become an interesting topic of discussion at present times. They have contributed to the most important element for the development of theories of second language acquisition and played an important part in second language principles and methods of instructions [1].

In the classroom practices, the most common and influential source of feedback to the students' writing errors is teacher. The teacher's types and strategies to correct foreign language or second language students' writing are necessary for student learning process. This indicates that providing feedback plays crucial roles in helping students to identify the erroneous part and help them to find the correct form in which it is as a part of their learning process. Feedback provided by teachers will further contribute to language 
learning. It is viewed as a means of promoting the growth of learner's motivation and improving the accuracy of language use [2] and development of students' potential and motivation in second language skills [3].

The ways the teachers providing feedback can be relatively different and varied from one context to the other because of the students' knowledge, individual preference and previous learning experiences [4]. Therefore, different types of feedback may be suitable for particular learners and target of corrections [5]-[8]. In most cases, the types of corrective feedback are categorized into two categories, the implicit and explicit corrective feedback [9]. In addition, the strategies of providing feedback to students' writing errors can influence the attainment of feedback provision [10]-[13].

The strategies of feedback can be categorized further into six [2], [14]. The first strategy is direct feedback. This feedback is characterized by a clear direction to correct the errors and a reformulation of the students' whole writing [1]. This feedback is appropriate for the learners who get difficulty to recognize the linguistic correct form. Research studies comparing the effectiveness of direct feedback to indirect feedback revealed that there were conflicting results between them. Studies conducted by Ferris and Robert, Ellis, Loewen and Erlam, [15], [16] indicate that for the students with low proficiency levels direct corrective feedback more applicable than corrective feedback provided indirectly. In the actual applications, indirect correction involves indicating that an error at the blank space surround the text or on the inside of the draft [1]. It is providing more learning on knowledge of high grammar in composition than direct feedback [17]. The research on teacher indirect written corrective feedback indicated that by providing underline of the writing's erroneous parts and suggesting the students to correct their own errors gave positive impacts for the improvement of the students' writing performance [5], [6], [18]-[20] and the structure as well as error-free writing draft [21]-[25]. In metalinguistic corrective feedback, the students are given feedback using some kinds of metalinguistic clues. In this strategy, the teacher may write codes in the margin or over the location of the error. Besides that, teacher described the errors of the language use at the lower side of the text [1], [2]. Moreover, Sritrakarn [20] indicate that metalinguistic written corrective feedback hints to correct the students' writing errors effectively.

Relating to the focus of feedback provision, some of the teachers attempt to correct all or most of the students' error. This feedback is categorized as unfocused feedback. On the other hand, other teacher may concentrate to provide a particular aspect of feedback of the students' language errors. Unlike unfocused corrective feedback, focused corrective feedback provides special emphasis on a particular linguistics aspect [2]. The effectiveness of providing feedback on particular aspects of errors or all aspects of errors may depend on the level of students' language proficiency [22], [24]-[28]. Meanwhile, Liu and Wu [29] reveal that teacher valued more highly on focused and indirect feedback. Finally, the type of corrective feedback is reformulation. Teacher implemented it by suggesting the learners to correct their writing errors by referring to the theories and linguistic explanation [2].

In addition, the teachers' perspectives influence their actual applications of providing written corrective feedback concerning the detail of their feedback, the time and effort expended and actual teacher's performance on the feedback [30], [31]. A study conducted by Lee, et al. [32] revealed that the actual applications of teachers' feedback were influenced by their perspectives. However, there are always some distinctions between the teachers viewed and acted in providing feedback. Lee [33] and Phipps and Borg [34] also indicate that there are a number of gaps such as the institutional context and values which may distract teachers to implement their perspectives into the actual applications.

In the actual applications of providing corrective feedback, teachers may be directed by their perspectives. It is as supported by the previous studies that it was necessary to integrate between the language pedagogy and teachers' actual applications and strategies in classroom [35]. Phipps and Borg [34] reveal that there was an interesting finding concerning the irrelevant practices of teachers' writing in the classroom and teachers' knowledge, cognition, and experiences. Other studies concerning beliefs and practices in written corrective feedback indicate that there were some mismatches between beliefs and practices of feedback [33], [36], [37].

Since there are undecipherable findings of the previous research on teachers' perspectives and actual applications of providing written corrective feedback to students' writing errors and the conflicting results of the previous study on the relationship between perspectives and applications of written corrective feedback provision. Therefore, this research aims at describing the English as a foreign language (EFL) university teachers' perspective in written corrective feedback and their actual applications. Moreover, it also aims at revealing if there is any correlation between the EFL university teachers' perspectives in providing written corrective feedback and their applications. 


\section{RESEARCH METHOD}

This research was conducted to describe the Indonesian EFL university teachers' perspectives and actual applications of written corrective feedback provisions and their correlation. The data was taken from 80 respondents' responses of the Google-form survey in which this number of participants has already fulfilled the minimum number of samples used in correlational research design [38]. The survey was distributed randomly to several university English teachers around Indonesia included Java, Bali, East Nusa Tenggara, and Sumatera. All of the respondents experienced of teaching English and providing feedback to the writing of the students in higher education levels for 1 year up to 30 years. Moreover, most of them experience of either teaching writing and English grammar and/or supervising students in thesis writing.

The survey used a Google-form questionnaire containing a set of questions to explore the teachers' perspectives and actual applications of the strategies in written corrective feedback provisions. This questionnaire comprised of both closed questions using Likert scale technique for the scoring purpose and open ended questions which let the respondents to answer truthfully concerning teachers' other perspectives and actual applications of feedback provisions. To obtain good and reliable information of the research, the assessment of reliability and validity of the Google-Form survey questionnaire was conducted. Pearson product-moment correlation and Cronbach's Alpha were used to measure the validity and reliability. From the result of the trying out of the questionnaires distributed to 23 participants, it was found out that each item of the questionnaire was valid at Pearson correlation value between 0.470 and 0.853 with the significant value $(\alpha)$ at 0.024 and 0.00 . Meanwhile each question in the actual applications part was valid at Pearson correlation value between 0.443 and 0.764 with the significant values between 0.034 and 0.00 . In addition, the reliability of the questionnaire was tested using Cronbach's Alpha, in which it was found out that the set of the questions in the questionnaire of the teacher's perspectives in feedback provision appeared to be reliable at the value of 0.836 and it was at 0.759 of teacher's actual application of feedback provision. Since the values of the Cronbach's Alpha were above 0.6, it indicated that all items in the two sets of questions in the questionnaire were reliable.

Finally, the analysis of the collected responses of the questionnaire was conducted involving the identification of the teachers' perspectives in written feedback provisions, general classification of the strategies of the teachers' actual applications in correcting students' writing errors and the correlation between the teachers' perspectives and their actual applications of feedback provisions. The data was analyzed using descriptive statistics and the correlation tests between teachers' perspectives and their actual application.

\section{RESULTS}

\subsection{Teachers' perspectives in written corrective feedback provision and their actual applications}

There were 18 items of the Google Form survey questioning the teachers' perspectives (from 1 to 9) and actual applications of feedback provision (from 10 to 18) as shown in Table 1. The teachers' responses regarding to the perspectives of the importance of feedback in improving the students' writing performance and varying the strategies of feedback are summarized in Figure 1.

The results of the survey indicated that most of the respondents which were $95 \%$ viewed that providing feedback to students' errors in writing was valuable. The mean score of the respondents' perspective in the importance of feedback provision was 4.65 with standard deviation 0.92 . It was only $5 \%$ of the respondents viewed that providing feedback to the students' writing errors was not necessary. In relation to varying strategies in providing feedback, it can be seen that $88.75 \%$ of the teachers viewed that varying the strategies of providing feedback was useful for helping the students improve their writing and the mean score was 4.2 with 0.79 standard deviation. On the other hand, $3.75 \%$ of teachers perceived that varying techniques in providing feedback was not necessary. Some teacher did not have any clear perspectives whether varying strategies of providing feedback was necessary or not $(7.5 \%)$. 
Table 1. University teachers' perspectives and actual applications of written corrective feedback provision

\begin{tabular}{|c|c|c|c|}
\hline No & Items & Mean & SD \\
\hline 1 & It is necessary for teachers to provide feedback on the students' errors in writing. & 4.65 & 0.92 \\
\hline 3 & Teachers should provide feedback on the student's errors selectively. & 3.90 & 1.07 \\
\hline 5 & $\begin{array}{l}\text { Coding errors with the help of marking codes is a useful means of helping students correct errors for } \\
\text { themselves. }\end{array}$ & 4.09 & 0.80 \\
\hline 6 & Marking codes should be easy for the students to follow and understand. & 4.30 & 0.74 \\
\hline 9 & Students should learn to analyze their own errors. & 4.16 & 0.79 \\
\hline 10 & I indicate (underline/circle/cross out/mark) the errors and correct them above or near the erroneous form. & 3.86 & 0.87 \\
\hline 11 & $\begin{array}{l}\text { I indicate (underline/circle/cross out/mark) errors, correct them and categorize them (with the help of } \\
\text { marking codes). }\end{array}$ & 3.30 & 0.91 \\
\hline 12 & I indicate (underline/circle/cross out/ mark) errors, but I don't correct them. & 2.90 & 1.13 \\
\hline 16 & I elect to correct all of the students' varieties of errors. & 2.80 & 1.16 \\
\hline 17 & I select specific error types for correction. & 2.58 & 1.06 \\
\hline 18 & $\begin{array}{l}\text { I correct the errors by providing the reformulated or corrected stories and ask students to study the errors for } \\
\text { about } 20 \text { minutes and take notes when necessary. }\end{array}$ & 2.88 & 1.14 \\
\hline
\end{tabular}

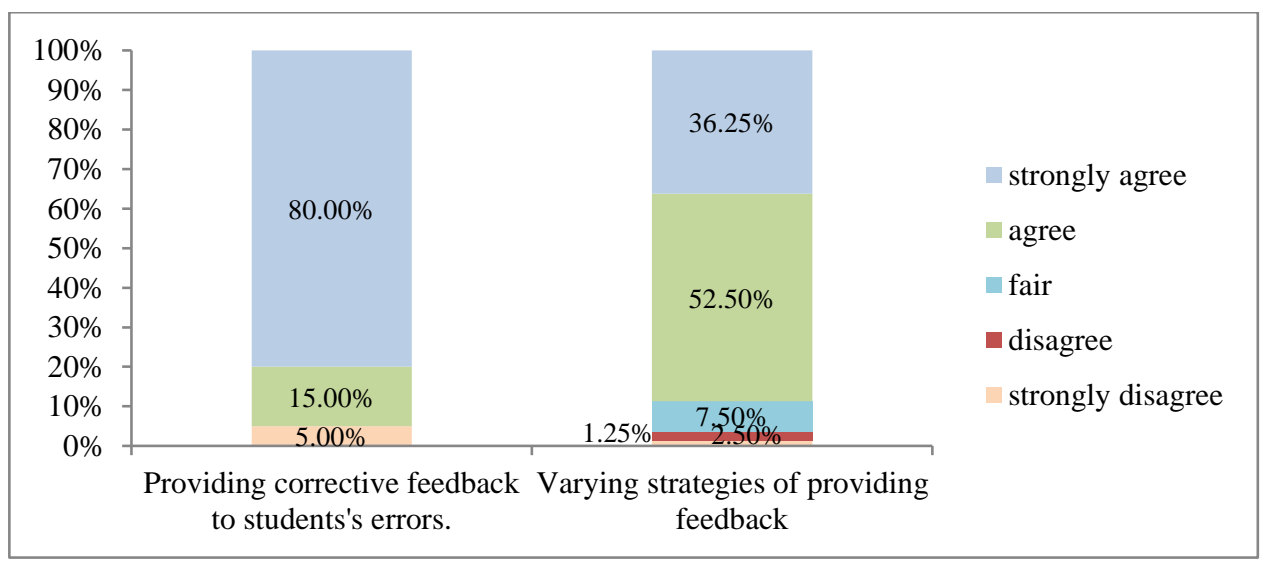

Figure 1. Teachers' perspectives in the importance and the varying the types of feedback

In case of teachers' perspectives on the four strategies of providing feedback of students' errors, it appears that most of the respondents had perspective that teachers only provide written feedback on the selected parts of errors $(76.25 \%$, with the mean score 3.9$)$. It was the largest standard deviation found in the perspectives of the feedback provision (1.07). However, it was only $10 \%$ of the respondents viewed that teacher should provide feedback on the overall errors that the students made in their writing. Meanwhile, $13.75 \%$ of the respondents were uncertain about whether teacher should provide corrections on the students' errors selectively or not. In addition, teachers also had perspectives that one of the writing teachers' jobs concerning the students' writing errors was to locate errors and provide corrections $60 \%$ (the mean score 3.75 with the standard deviation of 1.05). Meanwhile, only $11.25 \%$ of them said that they should not suggest the correction of errors by pointing the parts of errors and directly providing corrections and $28.7 \%$ of the teachers were ambivalent about correcting students' errors by locating and correcting errors. Moreover, teachers also perceived that providing feedback indirectly was useful. This indirect feedback can be done through using a particular code or mark to indicate students' errors. Most respondents (83.75\%) saw if the marking or coding was a useful strategy of helping students correct their errors (mean score 4.09 and deviation 0.80 ). It was only $3.5 \%$ of the respondents disagreed if coding and marking errors helped students in revising their writing's errors and $12.5 \%$ of the teachers were not sure of such strategies. Regarding the use of codes, most teacher that was $86.25 \%$ agreed if the codes used should be easily followed and understood by the students (mean score 4.30 and standard deviation 0.74 ), while $12.5 \%$ of them did not have any clear position about it. It was only $1.25 \%$ of the teachers believed if codes should not be understood and easily followed as seen in Figure 2. 


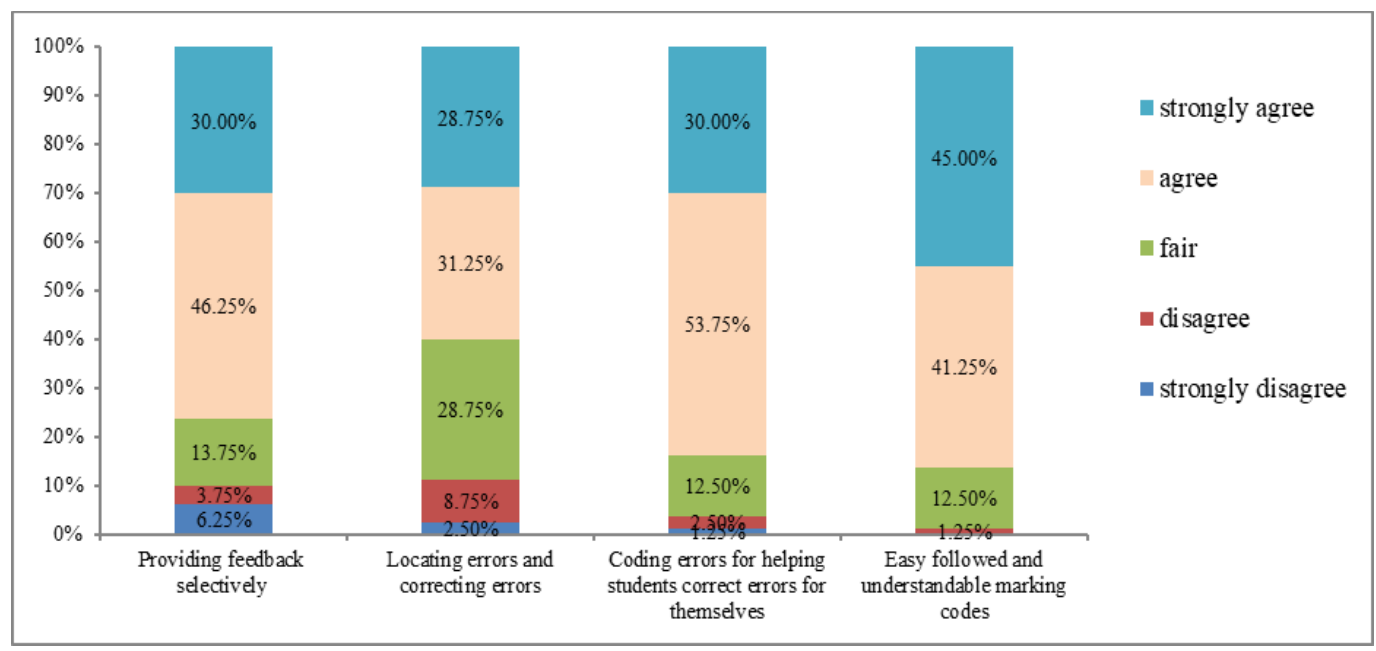

Figure 2. Teachers' perspectives in the strategies of feedback provisions

With respect to the teachers' points of view in the students' advantages of learning from doing selfcorrected feedback by indicating the errors and correcting their own errors, it appears that nearly all of the teachers viewed that it was important for the students to learn from correcting their own writing's errors. However, their perspectives in the roles of student in providing the kinds of feedback can be different. Figure 3 illustrates that an overwhelming majority of the teachers $(83.75 \%)$ saw that the students' selfcorrection of identifying their own writing's errors was necessary for their learning (the mean score 4.09). On the other hand, $6.25 \%$ of the teachers did not view that students should learn from identifying the parts of their own writing's errors. Meanwhile, some teachers were still doubt about the usefulness of students' selfcorrection (10\%). Moreover, most of the teachers $(80 \%)$ has a perspective that identifying and correcting the erroneous parts of writing was useful (mean score 4.01). Moreover, $12.5 \%$ of the teachers did not see it clearly whether identifying and correcting parts of their writing's errors were valuable for students' learning. Only $7.5 \%$ did not agree with the importance of recognizing and correcting their own writing's errors. In case of the teachers' perspectives in the students learning from analyzing their errors, $86.25 \%$ of the respondents saw that it was necessary (mean score 4.16 with standard deviation 0.79 ). However, there were few number of teachers $(5 \%)$ viewed that analyzing theirs their own writing's errors did not give opportunity of learning. In addition, $8.75 \%$ of the teachers were uncertain about it.

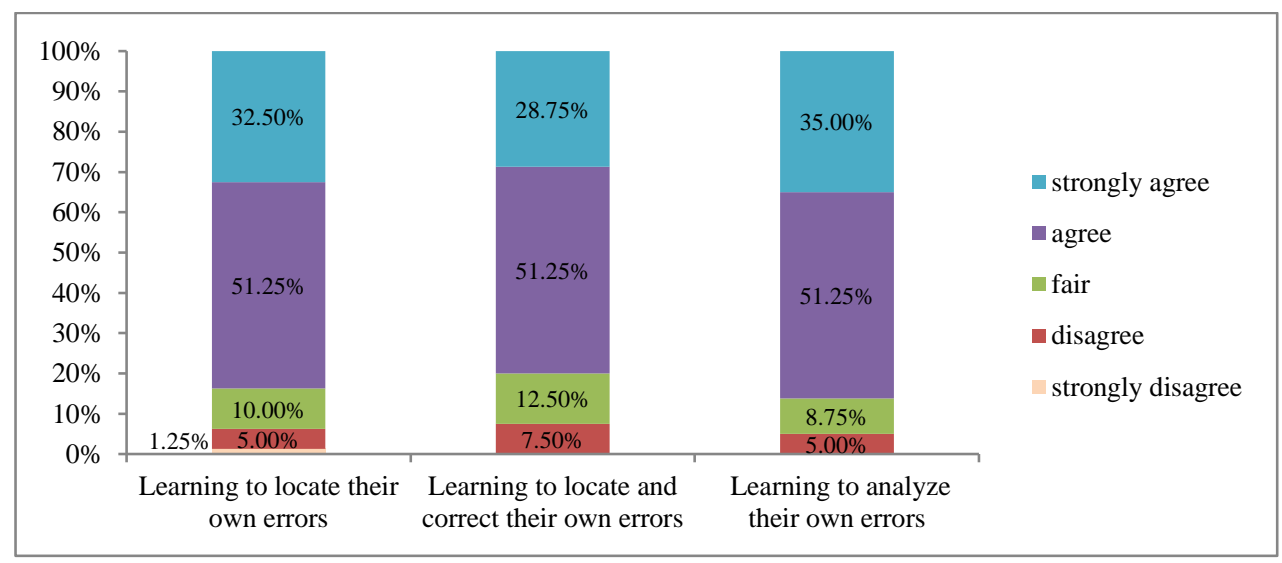

Figure 3. Teachers' perspectives in students' learning of identifying their own errors

With respect to the actual applications in written corrective feedback provisions, it is common for teachers to suggest direct correction by indicating the errors using underline, giving circle, crossing out or marking the error. The comments or corrections were also directly provided above or near the location of the errors. As seen in Figure 4, the majority of teacher respondents $(68.77 \%$ ) applied such feedback (mean score

EFL university teachers' perspectives in written corrective feedback and their ... (Windy Wahju Purnomo) 
3.86). From that number, $23.75 \%$ always and $45 \%$ often provided such correction. The least percentage of the teachers $(5 \%)$ never and rarely provided direct feedback using such marking, while $26.25 \%$ of the teachers sometimes practiced it. In addition, teachers might provide direct feedback using codes to and suggest the category of errors in which the mean score was 3.3 with the deviation 0.91 . Among the teachers who always and often applied direct corrective feedback using such strategy was $37.5 \%$ (10\% always and $27.5 \%$ often did it). They did the correction by indicating the errors using the code such as underline, circle, brackets or the other marks then correcting and categorizing. The majority of teachers (47.5\%) sometimes applied this feedback. Meanwhile some teachers never and rarely provided feedback to students' errors. They were respectively $2.5 \%$ and $12.5 \%$.

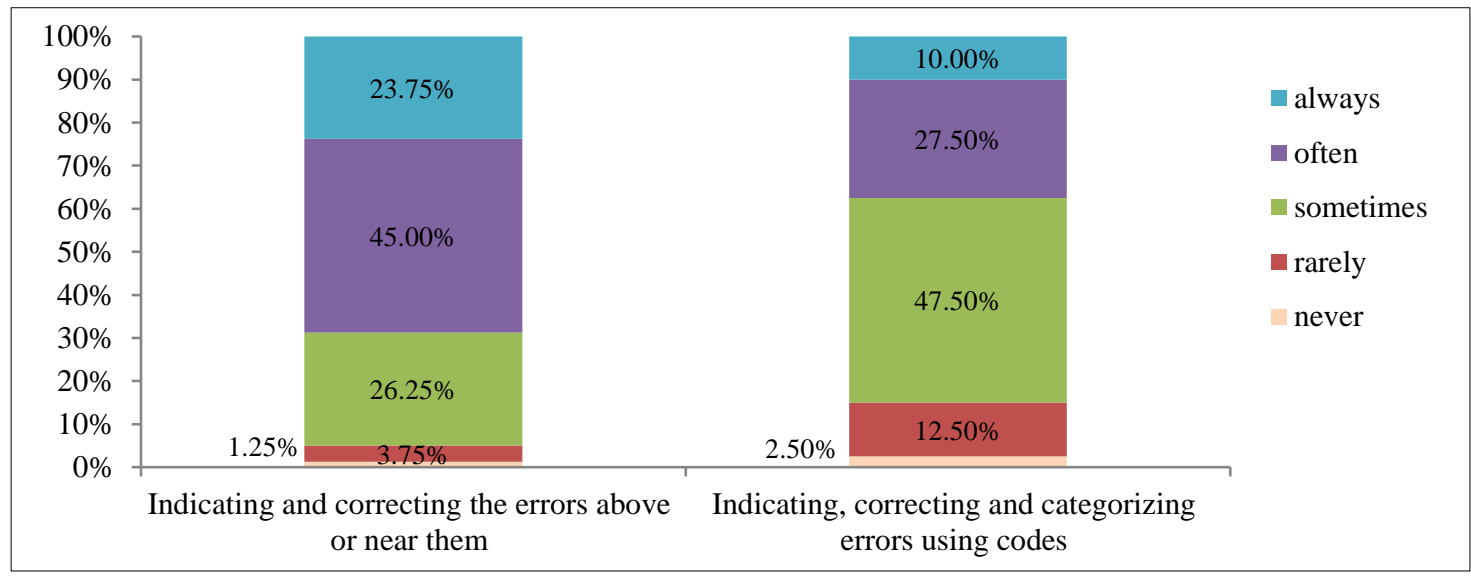

Figure 4. Teacher's applications of direct correction

In addition, the teachers' responses with respect to the actual applications of different strategies of providing indirect corrective feedback were summarized in Figure 5. The mean score of the actual applications of providing feedback to students' errors by indicating them without providing any correction was 2.90 (standard deviation 1.13). There was small number of teachers who always gave feedback to students' writing errors by indicating the errors using an underlined, circled, crossed out or marked signs without providing any correction of errors $(8.86 \%)$. In addition, $12.72 \%$ of the teachers often applied this type of corrective feedback. Most of the teachers (43.4\%) sometimes provided indirect correction in this way. Meanwhile the same amount of the teachers that was $15.19 \%$ never and rarely applied indirect correction through providing codes without any corrections given. The other actual classroom applications of indirect corrective feedback provision were given by showing the errors through underlining, drawing, circling, crossing out, or giving marks on the erroneous parts, and also categorizing the errors by providing a particular encryption but without giving the correct forms. The mean score of this actual application was 2.86 with the standard deviation of 1.03. The percentage of teachers who never experienced providing indirect feed using this strategy was $13 \%$ which was higher than the teachers who always used such strategy. Meanwhile, the teachers who sometimes applied indirect corrective feedback using codes was the highest (43\% of the participants). It is also found out that the same number of teachers that was $15.19 \%$ rarely and often did such correction. It is also found out that the teachers made indirect suggestions in the erroneous parts and drew a particular sign in the blank spaces that surround the text to point out the parts of the errors found in the students' writing (mean score 3.44). Half of the teachers always and often applied this strategy to correct the students' errors, and another $36.25 \%$ sometimes did it. Nevertheless, it was $7.5 \%$ of the teachers rarely used this strategy and only $6.25 \%$ of them never practiced it. In addition, the majority of the teachers who always and often made an indirect suggestion of the erroneous parts and the categorizations of errors with the help of marking codes (mean score 3.30) were respectively $10 \%$ and $41.25 \%$. Some teacher sometimes provided feedback using these strategies $(27.5 \%)$. The other $11.25 \%$ of the teachers rarely used this way of written correction and only $10 \%$ of them never applied such strategy. 


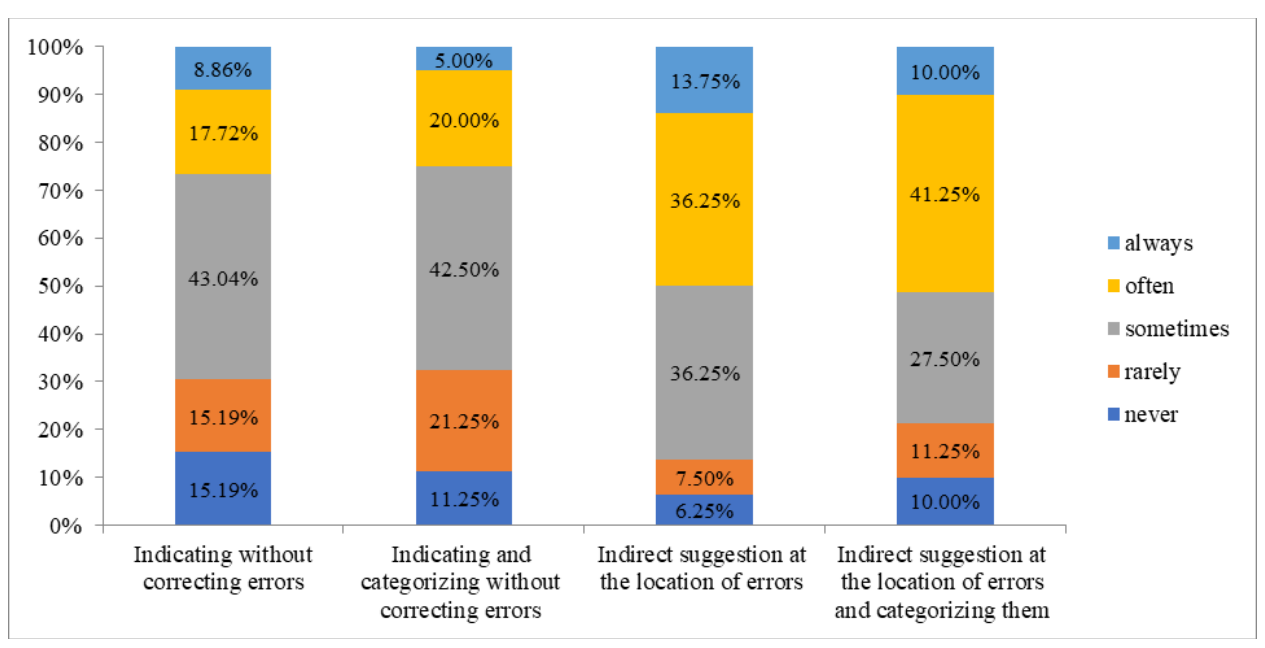

Figure 5. Teachers' actual applications of indirect feedback provisions

Table 1 indicates that the mean score of teacher actual applications of feedback provision through correcting all types of errors was 2.8. It also appears that the standard deviation for this item (item 16) was the highest at 1.16. From Figure 6, it reveals that the number of teachers who sometimes provided unfocused correction was $37.5 \%$ then followed by $21.5 \%$ of the teachers who often did such type of correction and it was only $7.5 \%$ of them always corrected all of the students' errors. $19 \%$ of the teachers never corrected the errors in such type. The rest $20 \%$ of them rarely did this typology of corrective feedback using this strategy. Meanwhile, in focused corrective feedback applications, teachers made a selection of correction from a number of students' writing errors, such as the article errors used rather than the other linguistic aspects (mean score 2.58). The greatest number of the teachers that was $37.50 \%$ sometimes did this focused correction and the least percentage of teachers that was $2.5 \%$ always did such corrective feedback. $16.25 \%$ of the teachers often did focused corrective feedback, $23.75 \%$ and $20 \%$ were rarely and never did such focused corrective feedback. The great number of the teacher sometimes corrected the erroneous parts of the students writing by providing the reformulated strategy or corrected stories (mean score 2.88). The correction can be written near the erroneous parts. This correction was conducted by asking the students to study the errors for about 20 minutes and take notes when it was necessary. It appears that only $7.5 \%$ and $21.75 \%$ of the teacher always and often did the reformulation strategy, and 37.5\% of the teachers sometimes applied it, and 20\% and $23.75 \%$ of them never and rarely corrected the students' errors through reformulation.

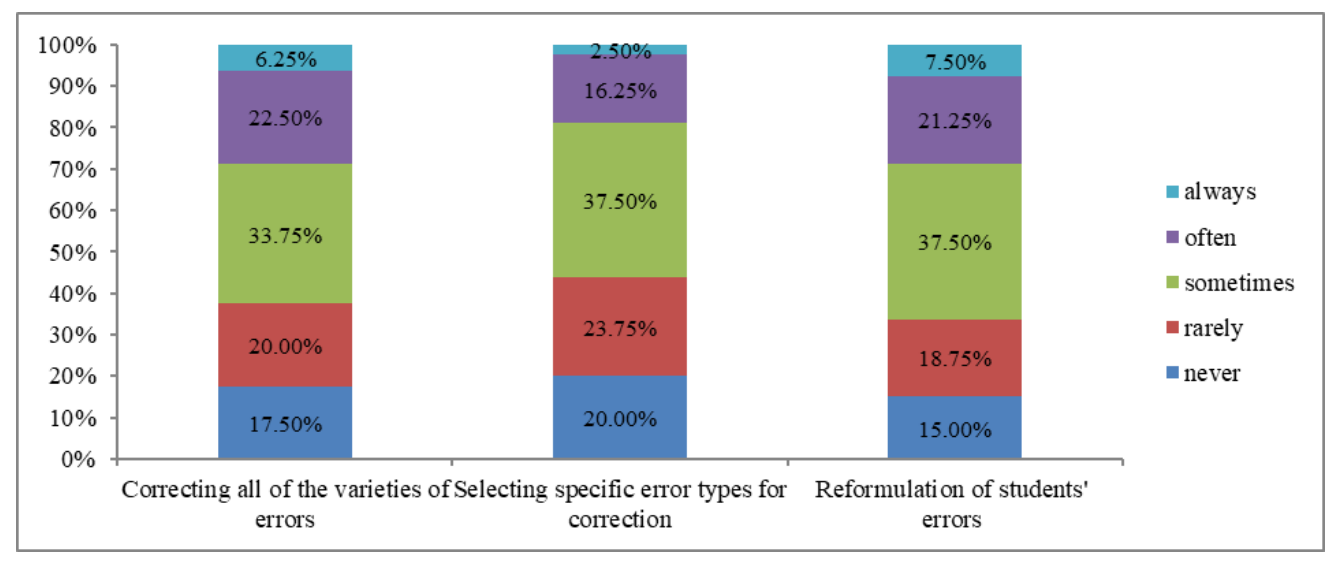

Figure 6. Teachers' applications of focus and reformulation of corrective feedback

In addition, $40 \%$ of the teacher participants had perspectives that the other strategies and some combinations of feedback were necessary. The examples of the other beliefs of feedback were such as considering students' emotions in providing feedback, the kinds of feedback motivating the students, and 
considering the details and number of feedback according to students' level of proficiency. Moreover, it appears that $27.5 \%$ of the teachers applied other feedback strategies. The other strategies were providing written corrective feedback with combination of class discussion, providing feedback with questions and answers, and indicating errors and giving opportunity to discuss with other friend to correct.

In their actual applications, teachers may combine one written feedback with the other ways of correction and it also found out that the teacher did the combination between the written and spoken corrective feedback. The finding from the open ended question revealed that the teacher also indirectly suggested the correction then he bring the case of errors to be discussed together with the other students in the classroom. This was the combination between indirect and reformulation may occur. It appears that teacher applied indirect corrective feedback by simply showing the students' writing's parts of errors using coloring pens without correction of errors provided. Meanwhile another teacher's actual classroom application of direct corrective feedback was also conducted by using coloring pens to indicate the errors of the students' writing and suggesting the students to correct their by discussing with friends.

Another actual application of the strategy in providing correction of students' writing errors is classified as the reformulation. It was conducted through providing explanation of the errors then asking the students to correct their own errors. It was also common that teachers applied combination of direct and indirect feedback. This combination of feedback strategies was applied by the teacher whenever the teachers understood the students have different level of linguistics and rhetorical writing competences. To correct the errors, a teacher also assigned the students to discuss and make the errors as a part of their homework. It was also found out that the teacher retype the errors then ask the students to discuss in small group with one proficient student to be peer teacher.

\subsection{The correlation between EFL university teachers' perspectives of written corrective feedback and their applications}

The third research question concerns with the correlation between the EFL university teachers' perspectives and actual applications of written corrective feedback provision to students' writing errors. The correlation analysis was conducted to find out the whether the EFL university teachers' perspectives on written corrective feedback provision influenced their actual applications. The result of the correlation analyzed using Pearson' correlation indicated in Table 2.

From the table of Pearson correlation computational statistics, it shows that the correlation was 0.264 in the significant number of 0.05 . It represents that there was a positive high correlation between teachers' perspectives in corrective feedback provision and the actual applications.

Table 2. Correlation between university teachers' perspectives and actual applications of written corrective feedback provision

\begin{tabular}{|c|c|c|c|}
\hline & & $\begin{array}{l}\text { Perspectives in written corrective } \\
\text { feedback provisions }\end{array}$ & $\begin{array}{l}\text { Actual applications of written corrective } \\
\text { feedback provisions }\end{array}$ \\
\hline \multirow{3}{*}{$\begin{array}{l}\text { Perspectives in written } \\
\text { corrective feedback }\end{array}$} & Pearson correlation & 1 & $.264 *$ \\
\hline & Sig. (2-tailed) & & .018 \\
\hline & $\mathrm{N}$ & 80 & 80 \\
\hline \multirow{3}{*}{$\begin{array}{l}\text { Actual applications of } \\
\text { written corrective feedback }\end{array}$} & Pearson correlation & $.264 *$ & 1 \\
\hline & Sig. (2-tailed) & .018 & \\
\hline & $\mathrm{N}$ & 80 & 80 \\
\hline
\end{tabular}

*Correlation is significant at the 0.05 level (2-tailed)

\section{DISCUSSION}

From the results of the study, it revealed that most of the teachers had perspectives if providing and varying strategies of feedback provisions were necessary and they also applied providing various feedback techniques on correcting the students' writing errors. It is as indicated in the previous studies that different strategies of providing feedback appropriate for particular learners and target of corrections [5]-[8]. The percentages of teachers' perspectives in the needs to locate and correct the errors and correcting the errors were consistent with their actual classroom applications. In addition, it also appears that the majority of teachers viewed that they needed to vary their feedback strategies. There were some reasons for varying the strategies of providing feedback such as the students' level of language proficiency and emotions, classroom context and the institutions. It is in line with the findings of the study conducted by Evans, et al. [10].

In case of the university teachers' perspectives on the focus of errors, it appears that most of the teachers viewed that not all students' writing errors were required to be corrected. It means that feedback is provided selectively. It is as supported by $\mathrm{Liu}$ and $\mathrm{Wu}$ [29]. The teachers also perceived that feedback 
provided can be done either directly or indirectly. However, more teachers perceived that indirect feedback is more effective to improve the quality of students' writing compared to direct feedback in which it is similar to the previous research findings [29]. In addition, they also had perspectives that correcting students' writing errors was given by indicating the erroneous parts using a particular codes or marks in which they must be easily followed and understood.

In case of the actual applications of providing direct or indirect feedback, it is discovered that most of the teachers always or often correct the students' writing errors by underlining, circling, crossing out or marking the error, and directly corrected above or near the location of the errors. Some teachers also added the categorization of errors. In addition, most of the teachers also sometimes provided feedback to students' errors indirectly. They only indicated the error parts but did not correct the errors. It is supported by the previous study conducted by Park, Song, and Shin [6]. Some of the teachers also applied reformulation feedback strategies. It was done by providing metalinguistic corrective feedback explanation about the students' areas of errors for example, it was conducted by providing a brief grammatical description on the parts of errors that students made. It appears that most of the teachers occasionally did reformulation feedback.

Finally, it is unlike previous studies which indicated that teachers' actual applications of correcting students' writing errors do not always represent their beliefs [33], [36]. The finding of this research indicated that Indonesia EFL university teachers' perspectives on the provision of written corrective feedback positively correlated with their actual applications. It indicates that there is high consistency between the teachers' perspectives and their actual applications of providing corrections to the students' writing errors. In addition, it is found out that there were many reasons which may cause the teacher to choose the different strategies in providing a certain strategy of feedback. Their different perspectives and actual applications differences of providing written corrective feedback were influenced by many factors likes teachers' experiences, students' cognition and levels of English proficiency, students and teacher's feeling or emotion, students' willingness to response feedback, time constraint, and the types of errors.

\section{CONCLUSION}

Taking consideration of the total number of Indonesian university teachers' perspectives in the importance of feedback provision, it is found out that nearly all of them agreed if the provision of feedback to students' writing errors was necessary. This fact indicates that the teachers should provide feedback to the university students' writings'. They also saw that teacher's correction can be done in various types through different strategies. In their writing classroom practices, the EFL university teachers applied different strategies of providing direct, indirect, metalinguistic, focused, unfocused and reformulation corrective feedback. From those feedback types, the direct feedback was mostly applied by the teachers. There were some reasons of applying a particular strategy of written corrective feedback provision. In addition, EFL university teachers' perspectives in providing written corrective feedback to students' writing errors positively correlated to their actual applications. It can be a challenge for teachers to recognize and be familiar with the various different types of corrective feedback. Therefore, they were also able to vary the strategies in giving corrective feedback in the effective and creative ways to achieve the objective of correcting and improving the quality of students' writing. Moreover, the majority of the teachers also had perspectives that the students were able to learn identifying their own errors and doing corrections without being given any direct comment on the errors.

The results of this study provide both theoretical and pedagogical implications. Theoretically, the findings of this research can enrich the body knowledge of the written corrective feedback and EFL student writing. Since teachers' perspectives of feedback provision to help students improve their writing influence their actual applications, teachers' knowledge and skills in providing feedback are required. Therefore, pedagogically, the teachers can improve their knowledge and perspectives of various feedback provision and their strategies by attending training of feedback and applying various feedback strategies in different teaching environment for various writing types and students with different proficiencies. This study hopefully helps teachers draw attention to the actual classroom applications of providing feedback strategies and rethink the practical methods of giving effective feedback to their students' writing errors in order to encourage the students learning to improve their writing performance. Therefore, it is able to reduce the different gap between the ideal and actual applications of feedback provisions.

Since this correlational study was applied to see the relationship between teachers' perspectives and actual applications of feedback with a particular number of participants in EFL context, further researchers are encouraged to do research investigation and discussion on the similar topics with larger participants in different cultural contexts and purposes using different research design. 


\section{REFERENCES}

[1] Y. Sheen and R. Ellis, "Corrective feedback in language teaching," In E. Hinkel, ed., Handbook of research in second language teaching and learning, vol. 2. New York: Routledge, 2011, pp. 593-610.

[2] R. Ellis, "Typology of Written Corrective Feedback Types," ELT Journal, vol. 63, no. 2, pp. 97-107, 2009.

[3] K. Hyland and F. Hyland, "Feedback on second language students' writing," Language Teaching, vol. 39, no. 02, pp. 83-101, 2006.

[4] I. Kozlova, "Ellis's corrective feedback in a problem-solving context," ELT Journal, vol. 64, no. 1, pp. 95-97, 2010.

[5] A. Jamalinesary, F. Rahimi, H. Gowhary, and A. Azizifar, "The Effects of Teacher Written Direct Vs Indirect Feedback on Students Writing," Social and Behavioral Sciences, vol. 192, pp. 116-123, 2015.

[6] E. S. Park, S. Song, and Y. K. Shin, "To what extent do learners benefit from indirect written corrective feedback? A study targeting learners of different proficiency and heritage language status," Language Teaching Research, vol. 20, no. 6, pp. 678-699, 2015.

[7] F. Poorebrahim, "Indirect Written Corrective Feedback, Revision, and Learning," Indonesian Journal of Applied Linguistics, vol. 6, no. 2, pp. 184-192, 2017.

[8] A. R. Septiana, G. H. Sulistyo, and A. E. Kadarisman "Corrective Feedback and Writing Accuracy of Students across Different Levels of Grammatical Sensitivity," Indonesian Journal of Applied Linguistics, vol. 6, no. 1, pp. 1-11, 2016.

[9] R. Lyster, K. Saito and M. Sato, "Oral corrective feedback in second language classrooms," Language Teaching, vol. 46, no. 1, pp. 1-40, 2012.

[10] N. W. Evans, K. J. Hartshorn, R. M. McCollum, and M. Wolfersberger, "Contextualizing corrective feedback in second language writing pedagogy," Language Teaching Research, vol. 14, no. 4, pp. 445-463, 2010.

[11] J. Muncie, "Using Written Teacher Feedback in EFL Composition Class," ELT Journal, vol. 54, no. 1, pp. 47-53, 2000.

[12] H. Nassaji, "Anniversary Article Interactional feedback in second language teaching and learning: A synthesis and analysis of current research," Language Teaching Research, vol. 20, no. 4, pp. 535-562, 2016.

[13] M-L. Ryoo, "The Effects of Teacher Feedback on EFL Students' Writing in a Korean University Class," The Journal of Asia TEFL, vol. 1, no. 1, pp. 115-130, 2004.

[14] R. Lyster and L. Ranta, "Corrective feedback and learner uptake: Negotiation of form in communicative classrooms," Studies in Second Language Acquisition, vol. 19, no. 1, pp. 37-66, 1997.

[15] D. R. Ferris and B. Roberts, "Error feedback in L2 writing classes: How explicit does it need to be?" Journal of Second Language Writing, vol. 10, no. 3, pp. 161-84, 2001.

[16] R. Ellis, S. Loewen, and R. Erlam, "Implicit Explicit Corrective Feedback and the Acquisition of L2 Grammar," Study in Second Language Acquisition, vol. 28, no. 2, pp. 339-368, 2006.

[17] S-K. Shin, "'Fire your proofreader!' Grammar correction in the writing classroom," ELT Journal, vol. 62, no. 4, pp. 358-36, 2008.

[18] K. E. Tan and Manochphinyo, "Improving Grammatical Accuracy in Thai Learners' Writing: Comparing Direct and Indirect Written Corrective Feedback," The Journal of Asia TEFL, vol. 14, no. 3, pp. 430-442, 2017.

[19] J. Chandler, "The Efficacy of Various Kinds of Error Feedback for Improvement in the Accuracy and Fluency of L2 Student Writing," Journal of Second Language Writing, vol. 12, no. 3, pp. 267-296, 2003.

[20] N. Sritrakarn, "Comparison of Teacher's and Senior Students' Feedback: Student Attitudes and their Writing Improvement," The Journal of Asia TEFL, vol. 15, no. 2, pp. 329-348, 2018.

[21] J. Bitchener, "Written Corrective Feedback for L2 Development: Current Knowledge and Future Research," Tesol Quarterly, vol. 46, no. 4, pp. 855-860, 2012.

[22] J. Bitchener, "Evidence in Support of Written Corrective Feedback," Journal of Second Language Writing, vol. 17, no. 2, pp. 102-118, 2008.

[23] J. Bitchener and U. Knoch, "The Relative Effectiveness of Different Types of Direct Written Corrective Feedback," System, vol. 37, no. 2, pp. 322-329, 2009.

[24] J. Bitchener and U. Knoch, "The Value of Written Corrective Feedback for Migrant and International Students," Language Teaching Research, vol. 12, no. 3, 409-431, 2008.

[25] Y. Sheen, "The Effect of Focused Written Corrective Feedback and Language Aptitude on ESL Learners' Acquisition of Articles," TESOL Quarterly, vol. 41, no. 2, pp. 255-283, 2007.

[26] J. Bitchener and U. Knoch, "The Contribution of Written corrective feedback to Language Development: A Ten Month Investigation," Applied Linguistics, vol. 31, no. 2, pp. 193-214, 2010.

[27] J. Bitchener and U. Knoch, "Raising the Linguistic Accuracy level of Advanced L2 Writers with Written Corrective Feedback," Journal of Second Language Writing, vol. 19, no. 4, pp. 207-217, 2010.

[28] R. Ellis, Y. Sheen, M. Murakami, and H. Takashima, "The effects of focused and unfocused written corrective feedback in an English as a foreign language context," System, vol. 36, no. 3, pp. 353-371, 2008.

[29] Q. Liu and S. Wu, "Same Goal, Varying Beliefs: How Students and Teachers see the Effectiveness of Feedback on Second Language Writing," Journal of Writing Research, vol. 11, no. 2, pp. 299-330, 2019.

[30] J. Tang, "Investigating University Tutor Perception of Assessment Feedback: three Types of Tutor Belief," Assessment \& Evaluation in Higher Education, vol. 36, no. 5, 2011.

[31] L. Zhan, "Written teacher Feedback: Student Perceptions, Teacher Perceptions, and Actual Teacher Performance," English Language Teaching, vol. 8, no. 8, pp. 583-604, 2016. 
[32] H. H. Lee, A. P. Leong, and G. Song "Integrating Teacher Perceptions of Feedback," ELT Journal, vol. 71, no. 1, pp. 60-68, 2017.

[33] I. Lee, "Ten Mismatches between Teachers' Beliefs and Written Practice," ELT Journal, vol. 63, no. 1, pp. 13-21, 2009.

[34] S. Phipps and S. Borg, "Exploring tensions between teachers' grammar teaching beliefs and practices," System, vol. 37, no. 3, pp. 380-390, 2009.

[35] S. Borg, "Teacher cognition in language teaching: A review of research on what language teachers think, know, believe, and do," Language Teaching, vol. 36, no. 2, pp. 81-109, 2003.

[36] S. Mao and P. Crosthwaite, "Investigating Written Corrective Feedback: (Mis) alignment of Teachers' Beliefs and Practice," Journal of Second Language Writing, vol. 45, pp. 46-60, 2019.

[37] L. Junqueira and C. Payant, "I just want to do it right, but it's so hard": A novice teacher's written feedback beliefs and practices," Journal of Second Language Writing, vol. 27, pp. 19-36, 2015.

[38] A. Mackey and S. M. Gass, Second Language Research: Methodology and design. New Jersey: Lawrence Erlbaum Associates, 2005. 